\title{
Three-Dimensional Phase Field Based Finite Element Study on Li Intercalation-Induced Stress in Polycrystalline $\mathrm{LiCoO}_{2}$
}

\author{
Linmin $\mathrm{Wu}^{1}$, Yi Zhang ${ }^{1}$, Yeon-Gil Jung ${ }^{2}$, Jing Zhang ${ }^{1, *}$ \\ ${ }^{1}$ Department of Mechanical Engineering, Indiana University-Purdue University Indianapolis, \\ Indianapolis, IN 46202, USA \\ ${ }^{2}$ School of Materials Science and Engineering, Changwon National University, \\ Changwon, Gyeongnam 641-773, Republic of Korea \\ *Email: jz29@iupui.edu; Phone: 317-278-7186; Fax: 317-274-9744
}

\begin{abstract}
In this study, the stress generation of $\mathrm{LiCoO}_{2}$ with realistic 3D microstructures has been studied systematically. Phase field method was employed to generate the 3D microstructures with different grain sizes. The effects of grain size, grain crystallographic orientation, and grain boundary diffusivity on chemical diffusion coefficient and stress generation were studied using finite element method. The calculated chemical diffusion coefficient is about in the range of $8.5 \times 10^{-10} \mathrm{~cm}^{2} / \mathrm{s}$ to $3.6 \times 10^{-9} \mathrm{~cm}^{2} / \mathrm{s}$. Stresses increase with the increase of grain size, due to more accumulation of $\mathrm{Li}$ ion near the grain boundary regions in larger grain size systems, which causes a larger concentration gradient. Failure is more likely to occur in large grain systems. The chemical diffusion coefficients increase with increasing grain orientation angle irrespective of grain boundary diffusivity, due to alignment of global $\mathrm{Li}$ ion diffusion path with high grain orientations. Grain boundary diffusivity has opposite effect on the hydrostatic stress. As small grain boundary diffusivity, the stress increases with increasing grain orientation angle, due to grain boundary blockage of Li ion diffusion. In contrast, with large grain boundary diffusivity,
\end{abstract}

This is the author's manuscript of the article published in final edited form as:

Wu, L., Zhang, Y., Jung, Y. G., \& Zhang, J. (2015). Three-dimensional phase field based finite element study on Li intercalation-induced stress in polycrystalline LiCoO 2. Journal of Power Sources, 299, 57-65.

http://dx.doi.org/10.1016/j.jpowsour.2015.08.082 
the stress decreases with increasing grain orientation angle due to reduced concentration gradients in grain boundary regions.

Key words: $\mathrm{LiCoO}_{2}$, grain size, grain orientation, grain boundary, diffusion, stress generation 


\section{Introduction}

Layered Li transition-metal oxides are widely used as active materials for positive electrodes in Li-ion rechargeable batteries [1], where intercalation of $\mathrm{Li}$ into metal oxides is one

of the most important phenomena that determines the performances of the batteries. The Li diffusion-induced stresses within electrode materials can lead to their fracture and failure which results in battery capacity loss and power fade. For $\mathrm{LiCoO}_{2}$, it is found that there exists the capacity fade about $2.2 \%$ and $6.5 \%$ for exchange of $0.5 \mathrm{Li}$ per $\mathrm{CoO}_{2}$ after 10 and 50 chargedischarge cycles, and the decrease of Co-O bond length was observed by using X-ray absorption spectroscopy [2]. A previous transmission electron microscopy (TEM) study showed that 20\% of the $\mathrm{LiCoO}_{2}$ particles were indeed fractured after 50 cycles at $0.2 \mathrm{C}$ between 2.5 and $4.35 \mathrm{~V}$ [3]. Thus, it is important to understand the $\mathrm{Li}$ intercalation stress with in the battery material.

In case of all solid state battery, recent experiment observation [4] has shown that secondary particles contain numerous grain boundaries, implying the primary particles are not completely isolated and most of the particles are not exposed to the electrolyte directly. Thus, intergranular diffusion between crystal grains plays a significant role in Li transport.

Many works have been done to understand how Li diffusion induced stresses can be minimized to increase the mechanical stability of Li-ion batteries [5-7]. Verbrugge and Cheng [5] numerically analyzed the stress and strain energy of a spherically-shaped electrode particle under a periodic voltage excitation source. They evaluated the crack nucleation using strain energy density method. Woodford et al. [6] derived a failure criterion and modeled the crack propagation in $\mathrm{Li}_{x} \mathrm{Mn}_{2} \mathrm{O}_{4}$ electrode particles under galvanostatic charging process. Zhao et al. [7] 
established the criterion for fracture of $\mathrm{Li}_{x} \mathrm{CoO}_{2}$ particles using diffusion kinetics and fracture mechanics. However, most of these works regarding Li transport simulations have adopted some assumptions, such as the isotropic grain properties and the sphere particle geometry. Thus, actual reaction kinetics and diffusion processes were simplified greatly, since the grain boundary and anisotropic diffusion processes were not taken into account. Recently, Han et al. [8] studied the grain boundary effect on $\mathrm{Li}$ effective diffusivity and intercalation stress of $\mathrm{LiMn}_{2} \mathrm{O}_{4}$. In their model, grain orientation was not considered, and each grain was simplified as Voronoi structure. Yamakawa et al. [9] did a numerical study of the phase field based Li diffusion in polycrystalline $\mathrm{LiCoO}_{2}$. However, their model was in two-dimension (2D), and $\mathrm{Li}$ intercalation stress was not calculated. Hence, some important features have not be captured using these models, especially in an inhomogeneous system. Thus, a microstructure based 3D Li transport and intercalationinduced stress model is warranted.

The phase field method is a promising technique [10] to describe the microstructural evolution on a mesoscale. The method has been applied to predict the evolution of the grain size and grain orientation distribution of a given grain structure [11, 12]. It has also been used to simulate the anisotropic electrochemical strain microscopy (ESM) response of polycrystalline $\mathrm{LiCoO}_{2}$ [13]. In this paper, the phase field method will be employed to simulate the evolution in polycrystalline $\mathrm{LiCoO}_{2}$ to generate a series of 3D microstructures with different grain sizes. Once the microstructures are obtained, the apparent chemical diffusivity and Li intercalationinduced stress will be studied based on the microstructures using finite element method.

This paper will be organized as the following: (1) the microstructures of 3D polycrystalline $\mathrm{LiCoO}_{2}$ with different grain sizes will be generated using the phase filed method. (2) The dependence of chemical diffusion coefficient on grain size, grain crystallographic orientation, 
and grain boundary will be systematically investigated. (3) The effect of grain size, grain crystallographic orientation, and grain boundary effects on $\mathrm{Li}$ intercalation-induced stress generation will be analyzed.

\section{Methods of calculation}

\subsection{Polycrystalline $\mathrm{LiCoO}_{2}$ microstructure generation}

In order to understand the relationship between the polycrystalline microstructures and $\mathrm{Li}$ diffusivity, four different microstructures of polycrystalline $\mathrm{LiCoO}_{2}$ were prepared using the phase field method, as described in $[10,11]$. The method describes the ideal grain growth with isotropic grain boundary energy and mobility.

In the phase-field model, the grain boundaries are considered as diffuse interfaces. The state of a point in the polycrystalline system of $\mathrm{Q}$ grains is given by order parameter $\phi_{\mathrm{q}}(\mathrm{q}=1$, $2, \ldots, \mathrm{Q}), \mathrm{q}$ is a grain's name. The evolution equation of the phase field is given by [11],

$$
\frac{\partial \phi_{q}}{\partial t}=M_{\phi}\left[\varepsilon^{2} \nabla^{2} \phi_{q}-\omega\left(1-2 \phi_{q}\right)\right]
$$

where $M_{\phi}$ is the isotropic phase-field mobility, $\varepsilon$ is the gradient energy coefficient, and $\omega$ is the height of parabolic potential with double obstacle.

The interface width $2 \xi$ and grain boundary energy $\mu$ for a boundary between two grains are given by [14],

$$
2 \xi=\pi \frac{\varepsilon}{\sqrt{2 \omega}} \quad, \quad \mu=\frac{\pi}{8} \varepsilon \sqrt{2 \omega}
$$

and $\mathrm{M} \phi$ has the relationship with the grain boundary energy $\mu$, width $2 \xi$ and mobility $\mathrm{m}$ [15], 


$$
M_{\phi}=\mu \frac{m}{\varepsilon^{2}}=\frac{\pi^{2}}{16} \frac{m}{\xi}
$$

In this study, $\xi=3, M_{\phi}=1$, and $\mu=1$ are chosen [11]. Other details are given in [11].

The generated microstructures are shown in Fig.1. Each color represents a different grain crystallographic orientation. The volume of the simulated polycrystalline $\mathrm{LiCoO}_{2}$ is $12.8 \times 12.8$ $\times 12.8 \mu \mathrm{m}^{3}$. According to reference [8], the average grain size of $\mathrm{LiCoO}_{2}$ is between $0.5 \mu \mathrm{m}$ to 5 $\mu \mathrm{m}$. The grain size of the generated microstructures are $1.84 \mu \mathrm{m}, 2.14 \mu \mathrm{m}, 2.56 \mu \mathrm{m}$, and $2.7 \mu \mathrm{m}$, respectively, which is in the range of the experimental observations. The grain boundaries are considered as thin films, which has a width of $10 \mathrm{~nm}$. After the phase field simulations, the microstructures are converted to an STL geometry file and then processed for meshing. The generated mesh is then imported into COMSOL Multiphysics for further simulations.

\section{2. $\quad$ Li diffusion in polycrystalline $\mathrm{LiCoO}_{2}$}

With the generated microstructures, the diffusion of $\mathrm{Li}$ ion in the polycrystalline $\mathrm{LiCoO}_{2}$ is carried out. There are three assumptions for the diffusion model in this study: (1) the diffusion obeys the Fick's 2nd law in grain and grain boundary; (2) No segregation effect in grain boundary is considered, and (3) the diffusivity of Li ion in grain boundary is smaller than that in the grain.

Due to the layered structure of $\mathrm{LiCoO}_{2}$, the diffusion pathway of $\mathrm{Li}$ ions in $\mathrm{LiCoO}_{2}$ single crystal is in two-dimensional [16]. Li ion has much smaller diffusion barriers along the $a-b$ axis plane, while it is very hard for Li ions to go across the $\mathrm{CoO}_{6}$ along the $c$ axis. In order to take the diffusion anisotropy into account, an anisotropic diffusion tensor need to be established. 
The relationship between the local coordinate system of Li diffusion and the global coordinate system is shown in Fig.2. The governing diffusion equation follows the Fick's 2nd Law:

$$
\frac{\partial c}{\partial t}=\nabla \cdot\left(-D^{\prime} \nabla c\right)
$$

where $\mathrm{c}$ is the concentration in $\mathrm{mol} / \mathrm{m}^{3}$, $\mathrm{D}^{\prime}$ is the anisotropic diffusion tensor. $\mathrm{D}^{\prime}$ can be written as,

$$
\left[D^{\prime}\right]=[Q]^{T}[D][Q]
$$

where [Q] is the rotation matrix based on the relationship between the local coordinate system of $\mathrm{Li}$ ion diffusion and the global coordinate system. $\mathrm{e}_{1}, \mathrm{e}_{2}$, and $\mathrm{e}_{3}$ represent the local coordinate system of Li ion diffusion. e ${ }_{1}^{\prime}, \mathrm{e}_{2}$ ', and e $_{3}$ ' represent the global coordinate system. The direction of $\mathrm{Li}$ ion transport is in $-\mathrm{e}_{1}{ }^{\prime} . \alpha$ and $\gamma$ are crystallographic orientation angles. The local coordinate system can be obtained by first rotating $\mathrm{e}_{3}$ ' axis angle $90^{\circ}-\alpha$ around $\mathrm{e}_{2}$ ' axis, then rotating angle $\gamma$ around $\mathrm{e}_{3}$ ' axis. In this case, 3D polycrystalline microstructures are used in the simulation. Thus, the orientation angles can be determined by $\alpha$ and $\gamma$ axes uniquely. When $\alpha$ and $\gamma$ are both $90^{\circ}$, the diffusion along $c$ axis is in perpendicular with the global Li transport direction. [D] is the diffusion tensor in the local coordinate system:

$$
[D]=\left[\begin{array}{ccc}
D_{\text {self }} & 0 & 0 \\
0 & D_{\text {self }} & 0 \\
0 & 0 & D_{\text {self-caxis }}
\end{array}\right]
$$

where $D_{\text {self }}$ is the diffusion coefficient along the $a-b$ axis plane, $D_{\text {self-caxis }}$ is the diffusion coefficient along the $c$ axis.

The grain boundaries in this case are considered as 3D surfaces between two grains without geometric thickness, and are described using the following equation: 


$$
-\vec{n} \cdot D_{g b}=\frac{D_{g b}}{d_{g b}}\left(c_{u}-c_{d}\right)
$$

where $n$ is the normal orientation of the grain boundary, $D_{g b}$ is the diffusion coefficient of the grain boundary, $d_{g b}$ is the width of the grain boundary. $c_{u}$ and $c_{d}$ represent the upper and lower concentration of the grain boundary, respectively. Since there is no reliable data of the diffusion coefficient of $D_{g b}$, we express the $D_{g b}$ using the following equation,

$$
D_{g b}=\beta D_{\text {self }}
$$

where $\beta$ is a positive constant $(0<\beta<=1)$. When $\beta$ is one, the grain boundary Li ion diffusivity is same as that in the grain. When $\beta$ is less than one, the diffusivity in grain boundary is less than that in the grain. In the inhomogeneous system with randomly oriented grains and grain boundaries, the simulation can be performed by solving equations (4) and (7) simultaneously.

\subsection{Validation of Li ion diffusion model}

In order to validate the diffusion model with experimental data, a 1D model is set up to simulate the dynamic stress tests (DST) as described in [17]. In the model, the cathode has a thickness of $1.6 \mu \mathrm{m}$. The electrolyte has a thickness of $7.5 \mu \mathrm{m}$. The Butler Volmer equation is used to describe the reaction kinetics for electrodes, as follows:

$$
J=\frac{i_{0}}{F}\left\{\exp \left[\frac{\alpha_{a} F}{R T}\left(\phi-U_{\text {OCP }}\right)\right]-\exp \left[-\frac{\alpha_{c} F}{R T}\left(\phi-U_{\text {OCP }}\right)\right]\right\}
$$

where $i_{0}$ is exchange current density, $\phi$ is the electrode potential, $\alpha_{a}$ and $\alpha_{c}$ are the anodic and cathodic transfer coefficient, respectively. F is the Faraday constant, R is the gas constant. T is 
temperature. The open-circuit potential (OCP) of the cathode material $\mathrm{LiCoO}_{2}$ UocP is obtained by fitting the OCP curve from Ref. [18].

The exchange current density $i_{0}$ is given by

$$
i_{0}=F k\left(c_{l}\right)^{\alpha_{a}}\left(c_{\max }-c_{s}\right)^{\alpha_{a}}\left(c_{s}\right)^{\alpha_{c}}
$$

where $\mathrm{k}$ is the kinetic rate constant of the electrochemical reaction, $\mathrm{c}_{\mathrm{s}}$ is the concentration of thee lithium ion on the surface of $\mathrm{LiCoO}_{2}$ electrode, cmax is the maximum $\mathrm{Li}$ concentration in $\mathrm{LiCoO}_{2}$, and $\mathrm{c}_{1}$ is the concentration of lithium ion in the electrolyte. The parameters are listed in Table 2.

The Li transport in the cathode obeyed the 2nd Fick’s law, and the Li transport in the electrolyte is described by Nerst-Plank equation. Additional model details are same as described in Ref. [19]. The applied current and the corresponding voltage response are shown in Fig.2. Overall, the simulation result is in good agreement with the experiment data in Ref. [17].

\section{4. $\quad$ Finite element method calculation of diffusivity}

After the model validation, the 3D simulations are performed using finite element method. The polycrystalline $\mathrm{LiCoO}_{2}$ volume is $12.8 \times 12.8 \times 12.8 \mu \mathrm{m}^{3}$. The temperature is set $300 \mathrm{~K}$. The boundary conditions of diffusion model are shown in Table 1. The initial Li ion concentration in the microstructures is fixed at $\mathrm{x}=0.6$ in $\mathrm{LixCoO}_{2}$. The inflow $\mathrm{Li}$ ion concentration are fixed at 0.61. The values of parameters are listed in Table 2. Refined meshes are employed near the grain boundaries to describe the interface between the grain and grain boundary.

The chemical diffusion coefficient can be evaluated using the following equation [20], 


$$
D_{a p p}=-\frac{d(\ln (\mathrm{dc} / \mathrm{dt}))}{d t} \frac{4 L^{2}}{\pi^{2}}, \quad \text { if } \quad t>L^{2} / D_{a p p}
$$

where $\mathrm{L}$ is the diffusion length along $\mathrm{x}$ axis.

Once the temporal evolution of Li ion concentration is evaluated, the chemical coefficient can be obtained using equation (11). With the time increase, the concentration increases from the initial concentration 0.6 to the inflow concentration 0.61 gradually. And the $\ln (\mathrm{dc} / \mathrm{dt})$ becomes a straight line after $\mathrm{t}>\mathrm{L}^{2} / \mathrm{D}_{\text {app }}$.

\section{5. $\quad \mathrm{Li}$ intercalation-induced stress in polycrystalline $\mathrm{LiCoO}_{2}$}

Experiment study [3] has showed the fracture of $\mathrm{LiCoO}_{2}$ particles during cycling, so it is important to include the stress generation during the intercalation process. During the intercalation process, the lattice constants change with the Li ion insertion [21], leading to stress generation.

The intercalation-induced stress can be expressed in analogy with thermal stress, and the modified Hooke's law [22] is expressed as:

$$
\varepsilon_{i j}=\frac{1}{E}\left[(1+v) \sigma_{i j}-v \sigma_{k k} \delta_{i j}\right]+\frac{\tilde{c} \Omega}{3} \delta_{i j}
$$

where $\varepsilon$ is strain, $\mathrm{E}$ is the Young's modulus, $v$ is the Poisson's ratio, $\sigma$ is stress. $\mathrm{c}=\mathrm{c}-\mathrm{c}_{0}$ is the concentration change from the initial stress free value. $\Omega$ is the partial molar volume.

Since the diffusion flux can be influenced by temperature, concentration, and stress field [23], the governing diffusion equation has the following expression: 


$$
\frac{\partial c}{\partial t}+\nabla \cdot\left(-D^{\prime}\left(\nabla c-\frac{\Omega c}{R T} \nabla \sigma_{h}\right)\right)=0
$$

where $\mathrm{c}$ is the concentration, $\mathrm{D}^{\prime}$ is the diffusion coefficient, $\Omega$ is the partial molar volume, $\mathrm{R}$ is the gas constant, $T$ is the absolute temperature and $\sigma_{h}=\left(\sigma_{11}+\sigma_{22}+\sigma_{33}\right) / 3$ is the hydrostatic stress. The boundary conditions of diffusion model are shown in Table 1.

\section{Results and discussion}

\subsection{Li diffusion in polycrystalline $\mathrm{LiCoO}_{2}$}

\subsubsection{Grain size and grain orientation effect}

The dependence of chemical diffusion coefficient $\mathrm{D}_{\text {app }}$ on grain size is investigated. The grain crystallographic orientation angles ( $\alpha$ and $\gamma$ ) are assigned to each grain randomly using a random number generation algorithm. The mean values of grain crystallographic orientation angles are given in Fig.3. In this study, the calculated chemical diffusion coefficient $\mathrm{D}_{\text {app }}$ is about in the range of $9.5 \times 10^{-10} \mathrm{~cm}^{2} / \mathrm{s}$ to $3.0 \times 10^{-9} \mathrm{~cm}^{2} / \mathrm{s}$ for $\beta=0.01$, and $1.85 \times 10^{-9} \mathrm{~cm}^{2} / \mathrm{s}$ to $3.6 \times 10^{-9} \mathrm{~cm}^{2} / \mathrm{s}$ for $\beta=1$. Mizushima et al. reported the chemical diffusivity of Li ion is about $5 \times 10^{-9} \mathrm{~cm}^{2} / \mathrm{s}$ from $\mathrm{Li}_{0.2} \mathrm{CoO}_{2}$ to $\mathrm{Li}_{0.8} \mathrm{CoO}_{2}$ using a transient experimental technique [24]. Jiang et al. used potentiostatic intermittent titration technique (PITT) to measure the chemical diffusion coefficient which is about $1 \times 10^{-9} \mathrm{~cm}^{2} / \mathrm{s}$ [25]. Our simulation results are consistent with the reported experimental results.

As shown in Fig.3, the chemical diffusion coefficients increase with the grain crystallographic orientation angles for both $\beta$ values. At higher angles, the Li ion diffusion 
direction is in alignment with the a-b axis plane, or the plane between $\mathrm{LiCoO}_{2}$ layered structures where a high Li ion high diffusion occurs.

The chemical diffusion coefficients also show grain size dependency for given orientation angles. When the grain size is large, the chemical diffusion coefficient increases more with increasing orientation angle than small grains systems. That implies the $\mathrm{D}_{\text {app }}$ is strongly influenced by the orientation angles for large grains systems. In small grains systems, there are more grain boundaries and orientation angles than large grains systems, leading to smaller deviation in the $\mathrm{D}_{\text {app. }}$. In large grain systems, there is no such a phenomenon. This can be also verified in Fig.4. For the grain sizes of $1.84 \mu \mathrm{m}$ and $2.14 \mu \mathrm{m}$, the $\mathrm{Li}$ ion diffusion shows more isotropic behavior than the grain sizes of $2.56 \mu \mathrm{m}$ and $2.70 \mu \mathrm{m}$, since there is less possibility for the systems of large grain size to compensate for the large difference of the orientation angles.

Another important feature is that the chemical diffusion coefficient has the trend of increase with the increase of the grain size. As shown in Fig.3, the $D_{\text {app }}$ increases as the mean value of the orientation angles increases from $30^{\circ}$ to $90^{\circ}$. When the mean of the orientation angles both reach $90^{\circ}$, the local diffusion pathway along c axis is perpendicular to the global $\mathrm{Li}$ transport direction, resulting in a larger chemical diffusion coefficient.

\subsubsection{Grain boundary effect}

When $\beta=1$, the grain boundary has the same diffusivity as that in the grain. When $\beta=0.01$, grain boundary has a smaller diffusivity than that in the grain. As shown in Fig.3, no matter how grain boundary diffusivity is varied, the chemical diffusion coefficients have the similar trend with respect to the various grain sizes and different orientation angles. At the same grain size and the same orientation angle, the chemical diffusion coefficient decreases with the decrease of the 
grain boundary diffusivity, implying the grain boundary network blocks the migration of Li ions. Overall, the chemical diffusivity of $\beta=1$ is about $20 \%$ higher than the case of $\beta=0.01$, because the later has a lower diffusivity at grain boundaries which reduce the overall chemical diffusion coefficient.

3.2 $\mathrm{Li}$ ion intercalation-induced stress generation in polycrystalline $\mathrm{LiCoO}_{2}$

\subsubsection{Grain size effect}

As shown in Fig.5, for both $\beta=0.01$ and $\beta=1$, the hydrostatic stresses increase with the increase of grain size. Larger grain size means lower grain boundary density, implying Li ions migrate much faster within large grain systems due to fewer grain boundaries which reduce Li ion diffusion. This result can be verified by Fig.6, which shows the hydrostatic stress profile for microstructures with different grain sizes. As shown in Fig.6, the stress increases with increasing grain size. Furthermore, larger grain size means higher energy release rate, implying failure is more likely to occur in larger grains. This conclusion is in agreement with [7].

\subsubsection{Grain orientation effect}

As orientation angles increase, for small grain boundary diffusivity $(\beta=0.01)$, stress increases due to accumulation of $\mathrm{Li}$ ion concentration in grain boundary regions. When the orientation angles reach $90^{\circ}$ which is parallel to the global $\mathrm{Li}$ transport direction, a larger amount of Li ions is blocked near the grain boundary regions, leading to the maximum stress at a certain grain size. In contrast, for large grain boundary diffusivity $(\beta=1)$, stress decreases due to reduced concentration gradients in grain boundary regions. When the orientation angles reach $90^{\circ}, \mathrm{Li}$ ions can migrate without the block of grain boundary, resulting in reduced stress. 


\subsubsection{Grain boundary effect}

As shown in Fig.5, grain boundary diffusivity $(\beta)$ has opposite effect on the hydrostatic stress. As $\beta=0.01$ or small grain boundary diffusivity, the stress increases with increasing grain orientation angle, as shown in Fig. 5 a. In contrast, as $\beta=1$, or large grain boundary diffusivity, the stress decreases with increasing grain orientation angle.

At small grain boundary diffusivity $(\beta=0.01)$, Li ions accumulate or are blocked near the grain boundary regions, leading to a large Li ion gradient. According to Eq. 12, large stress is generated with large concentration gradients. At higher grain orientation angles, the blocking effect is stronger, causing a higher concentration gradient, therefore, the stresses increase with increasing orientation angle. Moreover, the stresses of $\beta=0.01$ (Fig. 5a) are higher than those with $\beta=1$ (Fig. 5b).

For $\beta=1$, there is no distinction between the grain and grain boundary. The grain boundary diffusivity is same as that of grain. At higher grain orientation angles, Li ion are easy to diffuse through the microstructure, leading to a less concentration gradient. Thus the stresses decrease with increasing orientation angle. This results can be further proved by Fig.7. In Fig.7a, $\beta=0.01$ causes a slower $\mathrm{Li}$ ion diffusion than $\beta=1$, due to grain boundary blockage in $\beta=0.01$. The Li ion profile of $\beta=0.01$ has a larger concentration gradient, and consequently a lager stress than that of $\beta=1$, as shown in Fig. 7b.

\subsubsection{Time-dependent von Mises stress, hydrostatic stress and shear stresses}

The time history of averaged von Mises stress, hydrostatic stress and shear stresses of the microstructure with grain size $2.70 \mu \mathrm{m}, \beta=1$, and mean $\alpha=\beta=45^{\circ}$ is shown in Fig. 8 . The stresses are averaged on the entire model. The shear stresses along xz and xy directions are in a very 
small magnitude compared with the hydrostatic stress. With the time increase, both the hydrostatic stress and shear stress along yz direction increase monotonically, which is in agreement with Ref [26]. Additionally, the magnitude of the hydrostatic stress is three times larger than the shear stress along yz direction. Other grain size microstructures also follow the same trend. Our simulations show that the magnitudes of von Mises stress and hydrostatic stress are much higher than those of shear stresses. Therefore, hydrostatic stress is studied in this work, however, von Mises stress can also be used in failure criteria.

\section{Conclusion}

In this study, the $\mathrm{Li}$ intercalation-induced stresses in $\mathrm{LiCoO}_{2}$ with realistic 3D microstructures have been investigated using finite element method. The $\mathrm{LiCoO}_{2}$ microstructures with different grain sizes have been generated using phase field method. The effect of grain size, grain orientation and grain boundary on Li ion diffusion and stress has been systematically studied. The conclusions are summarized as follows:

(1) The chemical diffusion coefficient is about in the range of $8.5 \times 10^{-10} \mathrm{~cm}^{2} / \mathrm{s}$ to $3.0 \times 10^{-9}$ $\mathrm{cm}^{2} / \mathrm{s}$ for $\beta=0.01$, and $1.85 \times 10^{-9} \mathrm{~cm}^{2} / \mathrm{s}$ to $3.6 \times 10^{-9} \mathrm{~cm}^{2} / \mathrm{s}$ for $\beta=1$. The results are consistent with the experimental data in literature.

(2) The chemical diffusion coefficients increase with increasing grain orientation angle irrespective of grain boundary diffusivity, due to alignment of global $\mathrm{Li}$ ion diffusion path with high grain orientations. For large grain system, the chemical diffusion coefficient increases more than those of small grain systems, because dominant grain diffusion of large grain system at higher grain orientations. 
(3) The chemical diffusion coefficients decrease with the decrease of the grain boundary diffusivity, due to blocking behavior of grain boundaries.

(4) Grain boundary diffusivity has opposite effect on the hydrostatic stress. As $\beta=0.01$ or small grain boundary diffusivity, the stress increases with increasing grain orientation angle, due to grain boundary blockage of Li ion diffusion. In contrast, as $\beta=1$, or large grain boundary diffusivity, the stress decreases with increasing grain orientation angle due to reduced concentration gradients in grain boundary regions.

(5) Stresses increase with the increase of grain size, due to more accumulation of Li ion near the grain boundary regions in larger grain size systems, which causes a larger concentration gradient. Failure is more likely to occur in large grain systems. 


\section{References}

1. Tarascon, J.M. and M. Armand, Issues and challenges facing rechargeable lithium batteries. Nature, 2001. 414(6861): p. 359-367.

2. Yoon, W.-S., et al., Oxygen Contribution on Li-Ion Intercalation-Deintercalation in $\mathrm{LiCoO}_{2}$ Investigated by $O \mathrm{~K}$-Edge and Co L-Edge X-ray Absorption Spectroscopy. The Journal of Physical Chemistry B, 2002. 106(10): p. 2526-2532.

3. Wang, H., et al., TEM Study of Electrochemical Cycling-Induced Damage and Disorder in $\mathrm{LiCoO}_{2}$ Cathodes for Rechargeable Lithium Batteries. Journal of The Electrochemical Society, 1999. 146(2): p. 473-480.

4. Wilson, J.R., et al., Measurement of three-dimensional microstructure in a $\mathrm{LiCoO}_{2}$ positive electrode. Journal of Power Sources, 2011. 196(7): p. 3443-3447.

5. Verbrugge, M.W. and Y.-T. Cheng, Stress and Strain-Energy Distributions within DiffusionControlled Insertion-Electrode Particles Subjected to Periodic Potential Excitations. Journal of The Electrochemical Society, 2009. 156(11): p. A927-A937.

6. Woodford, W.H., Y.-M. Chiang, and W.C. Carter, "Electrochemical Shock" of Intercalation Electrodes: A Fracture Mechanics Analysis. Journal of The Electrochemical Society, 2010. 157(10): p. A1052-A1059.

7. Zhao, K., et al., Fracture of electrodes in lithium-ion batteries caused by fast charging. Journal of Applied Physics, 2010. 108(7): p. 074517.

8. Han, S., et al., Numerical study of grain boundary effect on $\mathrm{Li}^{+}$effective diffusivity and intercalation-induced stresses in Li-ion battery active materials. Journal of Power Sources, 2013. 240(0): p. 155-167.

9. Yamakawa, S., et al., Numerical study of Li diffusion in polycrystalline $\mathrm{LiCoO}_{2}$. Journal of Power Sources, 2013. 223: p. 199-205.

10. Moelans, N., B. Blanpain, and P. Wollants, Quantitative analysis of grain boundary properties in a generalized phase field model for grain growth in anisotropic systems. Physical Review B, 2008. 78(2): p. 024113.

11. Kim, S.G., et al., Computer simulations of two-dimensional and three-dimensional ideal grain growth. Physical Review E, 2006. 74(6): p. 061605.

12. Moelans, N., B. Blanpain, and P. Wollants, Phase field simulations of grain growth in twodimensional systems containing finely dispersed second-phase particles. Acta Materialia, 2006. 54(4): p. 1175-1184.

13. Chung, D.-W., et al., Virtual Electrochemical Strain Microscopy of Polycrystalline LiCoO 2 Films. Journal of The Electrochemical Society, 2011. 158(10): p. A1083-A1089.

14. Steinbach, I. and F. Pezzolla, A generalized field method for multiphase transformations using interface fields. Physica D: Nonlinear Phenomena, 1999. 134(4): p. 385-393.

15. Gyoon Kim, S., et al., Phase-field modeling of eutectic solidification. Journal of Crystal Growth, 2004. 261(1): p. 135-158.

16. Andriyevsky, B., K. Doll, and T. Jacob, Electronic and transport properties of $\mathrm{LiCoO}_{2}$. Physical Chemistry Chemical Physics, 2014. 16(42): p. 23412-23420.

17. Zhang, L., et al., Multi-objective optimization of lithium-ion battery model using genetic algorithm approach. Journal of Power Sources, 2014. 270: p. 367-378.

18. Zhang, Q., Q. Guo, and R.E. White, A New Kinetic Equation for Intercalation Electrodes. Journal of The Electrochemical Society, 2006. 153(2): p. A301-A309.

19. Danilov, D., R.A.H. Niessen, and P.H.L. Notten, Modeling All-Solid-State Li-Ion Batteries. Journal of The Electrochemical Society, 2011. 158(3): p. A215-A222. 
20. Wen, C.J., et al., Thermodynamic and Mass Transport Properties of "LiAl " Journal of The Electrochemical Society, 1979. 126(12): p. 2258-2266.

21. David, W.I.F., et al., Structure refinement of the spinel-related phases $\mathrm{Li}_{2} \mathrm{Mn}_{2} \mathrm{O}_{4}$ and $\mathrm{Li}_{0.2} \mathrm{Mn}_{2} \mathrm{O}_{4}$. Journal of Solid State Chemistry, 1987. 67(2): p. 316-323.

22. Yang, F., Interaction between diffusion and chemical stresses. Materials Science and Engineering: A, 2005. 409(1-2): p. 153-159.

23. Wang, W.L., S. Lee, and J.R. Chen, Effect of chemical stress on diffusion in a hollow cylinder. Journal of Applied Physics, 2002. 91(12): p. 9584-9590.

24. Mizushima, K., et al., $\mathrm{Li}_{x} \mathrm{CoO}_{2}(0<x \leqslant 1)$ : A new cathode material for batteries of high energy density. Solid State Ionics, 1981. 3-4: p. 171-174.

25. Jang, Y.-I., B.J. Neudecke, and N.J. Dudney, Lithium Diffusion in $\mathrm{Li}_{x} \mathrm{CoO}_{2}(0.45<x<0.7)$ IntercalationCathode. Electrochemical and Solid-State Letters, 2001. 4(6): p. A94-A77.

26. Cheng, Y.-T. and M.W. Verbrugge, Evolution of stress within a spherical insertion electrode particle under potentiostatic and galvanostatic operation. Journal of Power Sources, 2009. 190(2): p. 453-460. 


\section{List of figures}

Fig. 1 3D polycrystalline $\mathrm{LiCoO}_{2}$ microstructures generated using phase-field method. Each color represents different crystallographic grain orientation. (a) average grain size $1.84 \mu \mathrm{m}$; (b) average grain size $2.14 \mu \mathrm{m}$; (c) average grain size $2.56 \mu \mathrm{m}$; and (d) average grain size $2.7 \mu \mathrm{m}$.

Fig. 2 Simulated dynamic stress test. (a) applied current with respect to time as the model input. (b) Simulated response of voltage with respect to time, which is good agreement with experimental data [15].

Fig. 3 Dependence of chemical diffusion coefficient Dapp and the orientation angles for four microstructures with different grain sizes. (a) $\beta=0.01$. (b) $\beta=1$. Dashed lines are guide to the eyes.

Fig. $4 \mathrm{Li}$ ion concentration profiles (mole fraction $\mathrm{x}$ in $\mathrm{Li}_{\mathrm{x}} \mathrm{CoO}_{2}$ ) in four $\mathrm{Li}$ ion diffusion microstrucutre models, at $50 \mathrm{~s}$ for $\beta=0.01$. (a) Grain size is $1.84 \mu \mathrm{m}$. (b) Grain size is $2.14 \mu \mathrm{m}$. (c) Grain size is $2.56 \mu \mathrm{m}$. (d) Grain size is $2.70 \mu \mathrm{m}$.

Fig. 5 Dependence of the hydrostatic stress on various grain sizes and different orientation angles. (a) $\beta=0.01$ (b) $\beta=1$. Dashed lines are guide to the eyes.

Fig. 6 Hydrostatic stress profiles for microstructures with different grain sizes. The profile shown is a cut plane at $\mathrm{z}=6.4 \mu \mathrm{m}$ at $\mathrm{t}=50 \mathrm{~s}, \beta=0.01$, mean $\alpha=\beta=45^{\circ}$. (a) Grain size is $1.84 \mu \mathrm{m}$. (b) Grain size is $2.14 \mu \mathrm{m}$. (c) Grain size is $2.56 \mu \mathrm{m}$. (d) Grain size is $2.70 \mu \mathrm{m}$.

Fig. 7 (a) Li ion concentration (mole fraction $\mathrm{x}$ in $\mathrm{Li}_{\mathrm{x}} \mathrm{CoO}_{2}$ ) profiles; and (b) Hydrostatic stress profiles for $1.84 \mu \mathrm{m}$ with different grain boundary diffusivities. The plane shown is a cut plane at $\mathrm{z}=6.4 \mu \mathrm{m}$, $\mathrm{t}=50 \mathrm{~s}$, and orienation angle $30^{\circ}$.

Fig. 8 Time history of averaged von Mises stress, hydrostatic stress and shear stresses of the microstructure with grain size $2.70 \mu \mathrm{m}, \beta=1$, and mean $\alpha=\beta=45^{\circ}$. 


\section{List of tables}

Table 1 Boundary conditions

Table 2 Parameters used in the simulation 


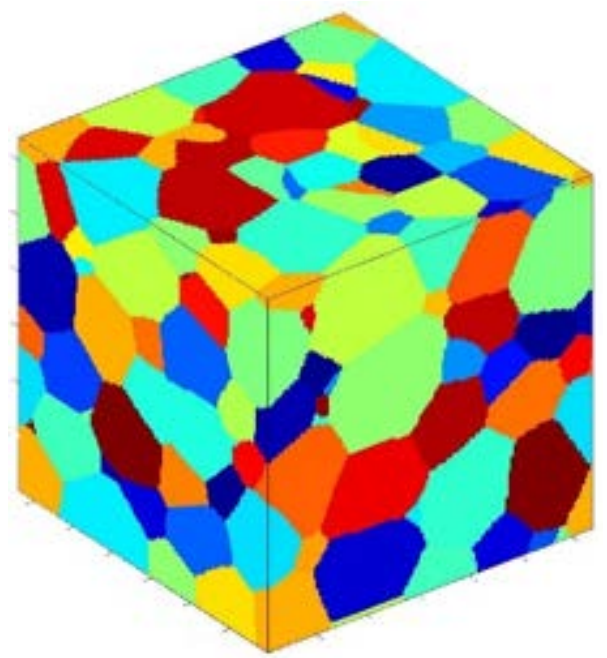

(a)

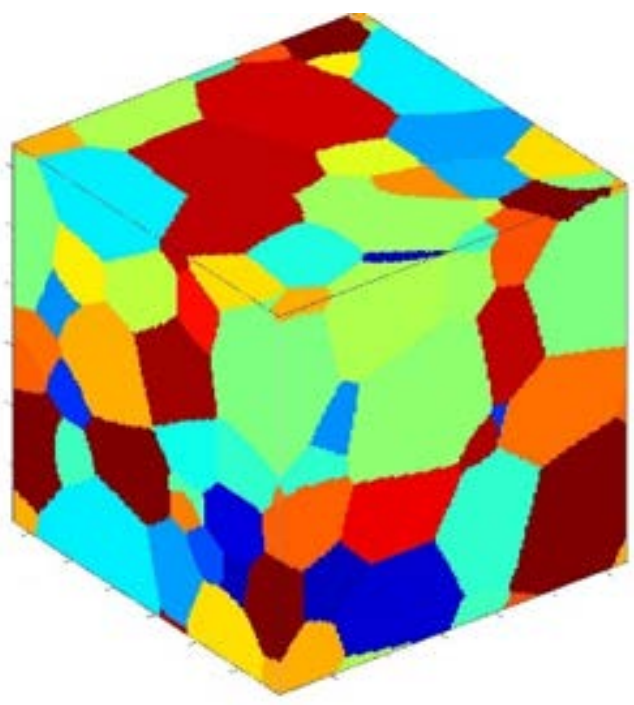

(b) 


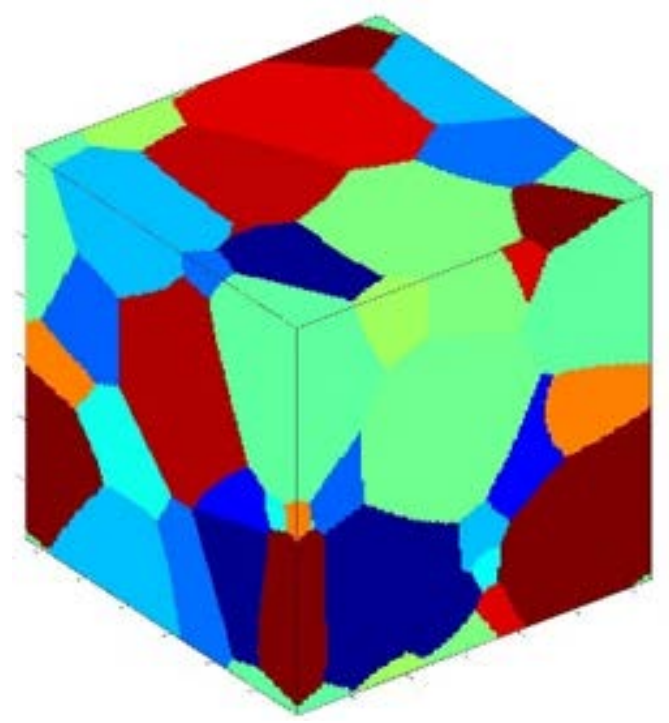

(c)

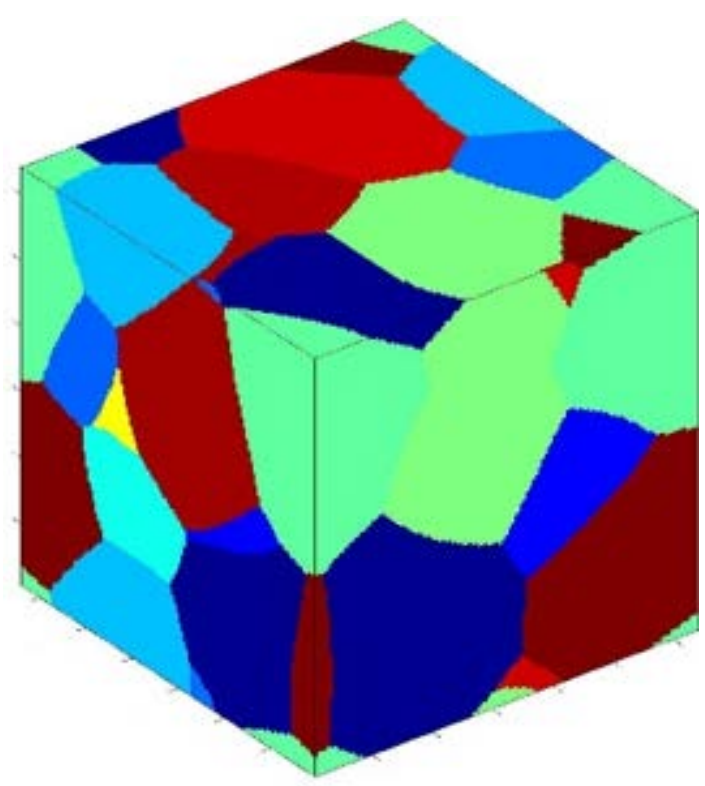

(d)

Fig. 1 3D polycrystalline $\mathrm{LiCoO}_{2}$ microstructures generated using phase-field method. Each color represents different crystallographic grain orientation. (a) average grain size $1.84 \mu \mathrm{m}$; (b) average grain size $2.14 \mu \mathrm{m}$; (c) average grain size $2.56 \mu \mathrm{m}$; and (d) average grain size $2.7 \mu \mathrm{m}$. 


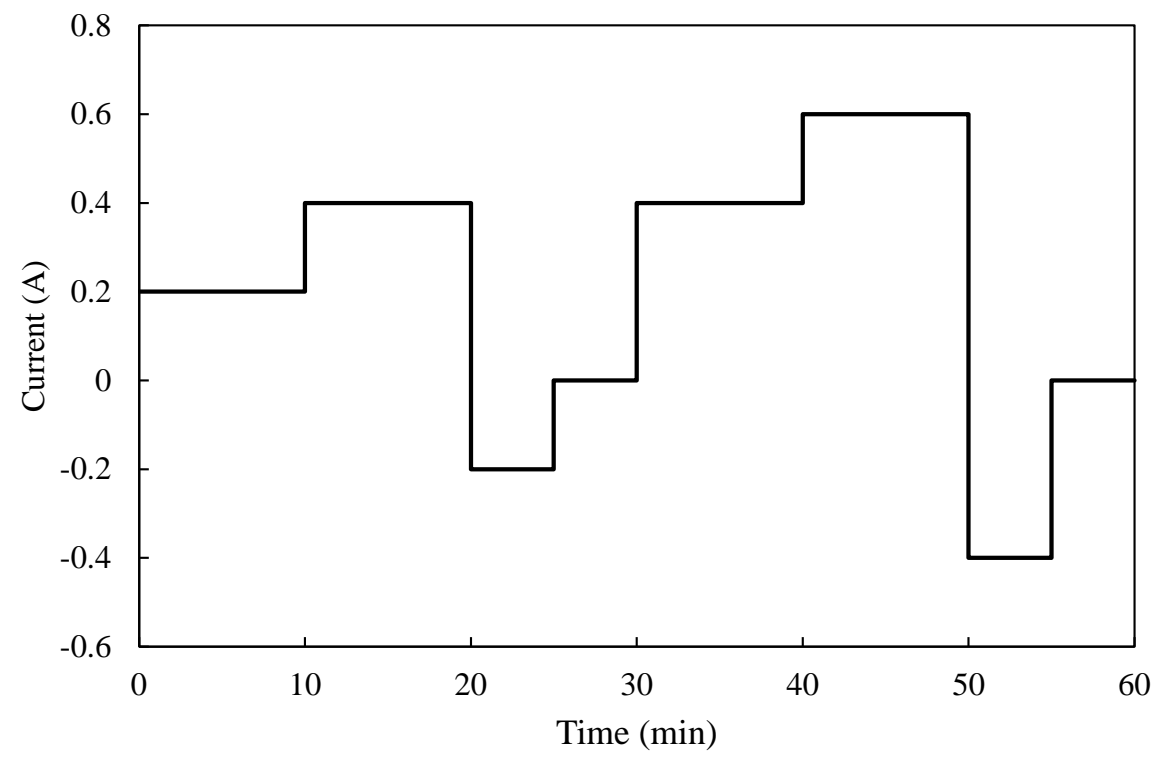

(a)

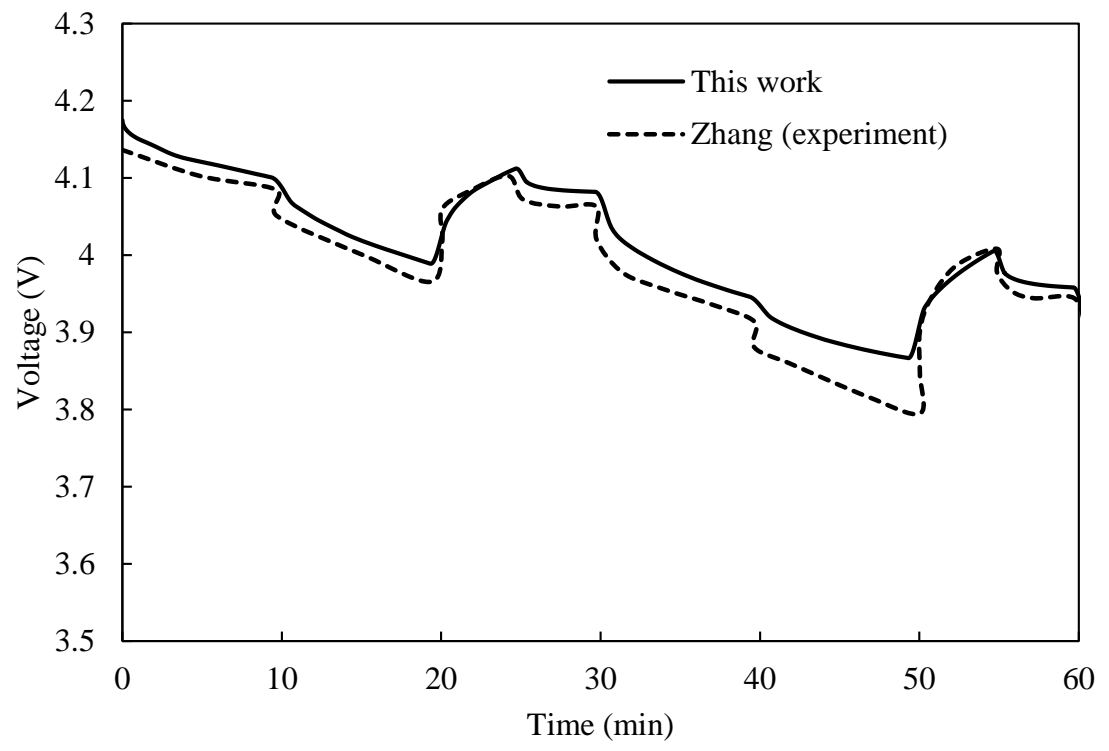

(b)

Fig. 2 Simulated dynamic stress test. (a) applied current with respect to time as the model input. (b) Simulated response of voltage with respect to time, which is good agreement with experimental data [15]. 


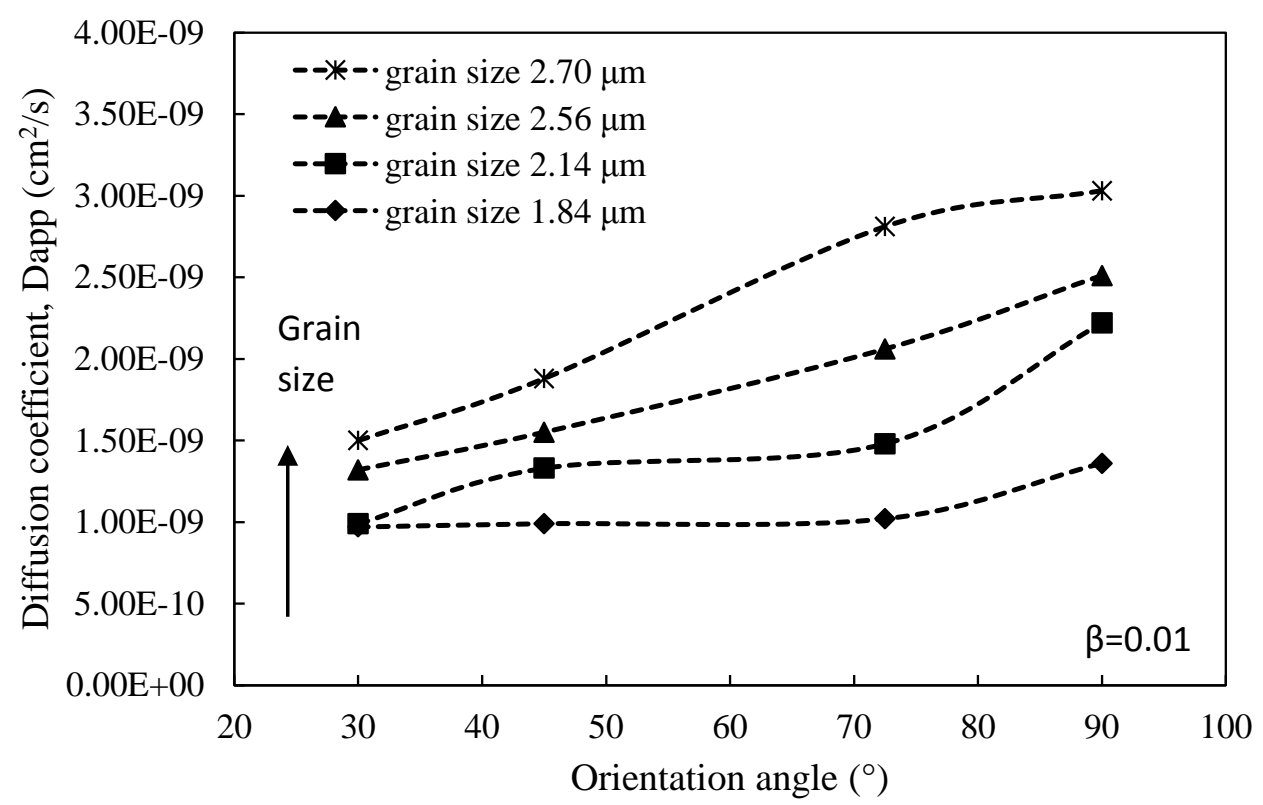

(a)

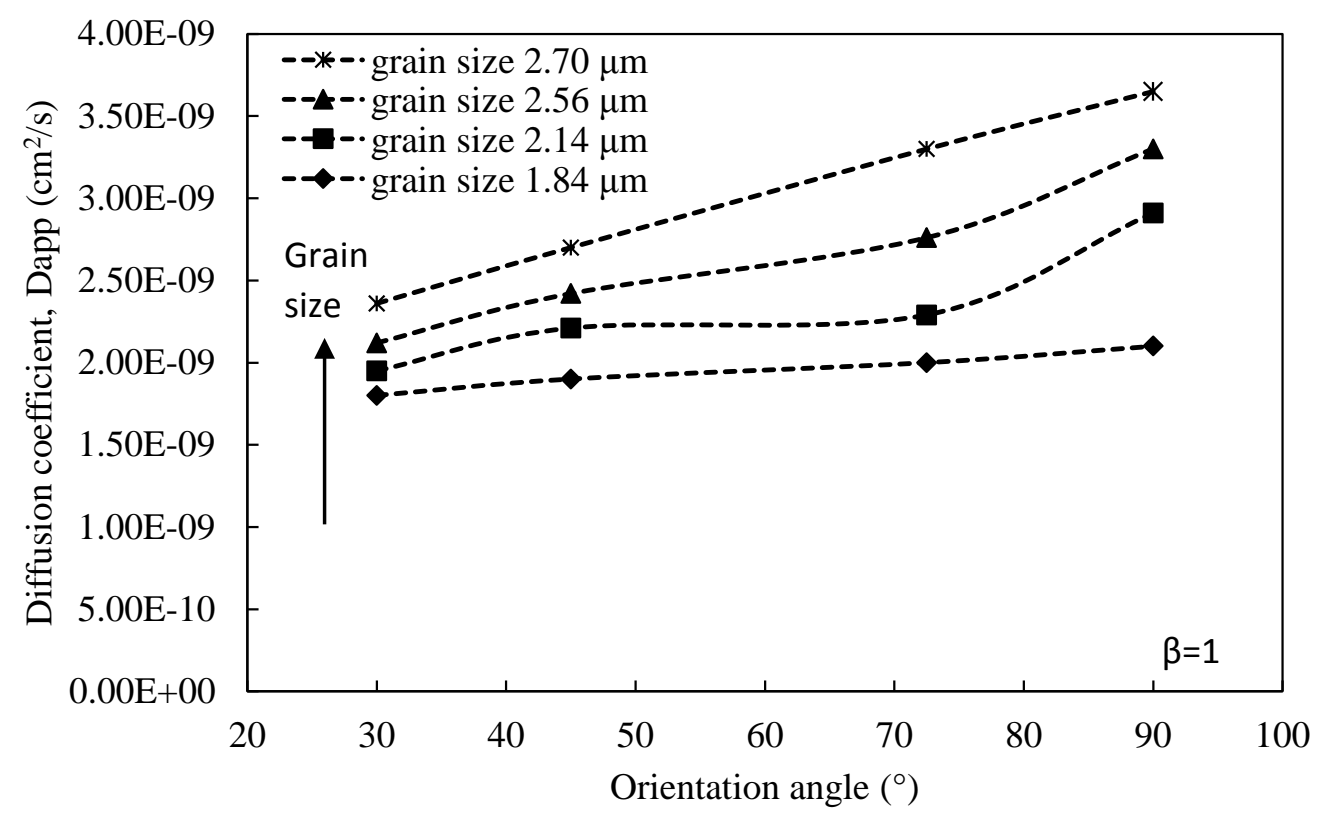

(b)

Fig. 3 Dependence of chemical diffusion coefficient Dapp and the orientation angles for four microstructures with different grain sizes. (a) $\beta=0.01$. (b) $\beta=1$. Dashed lines are guide to the eyes. 


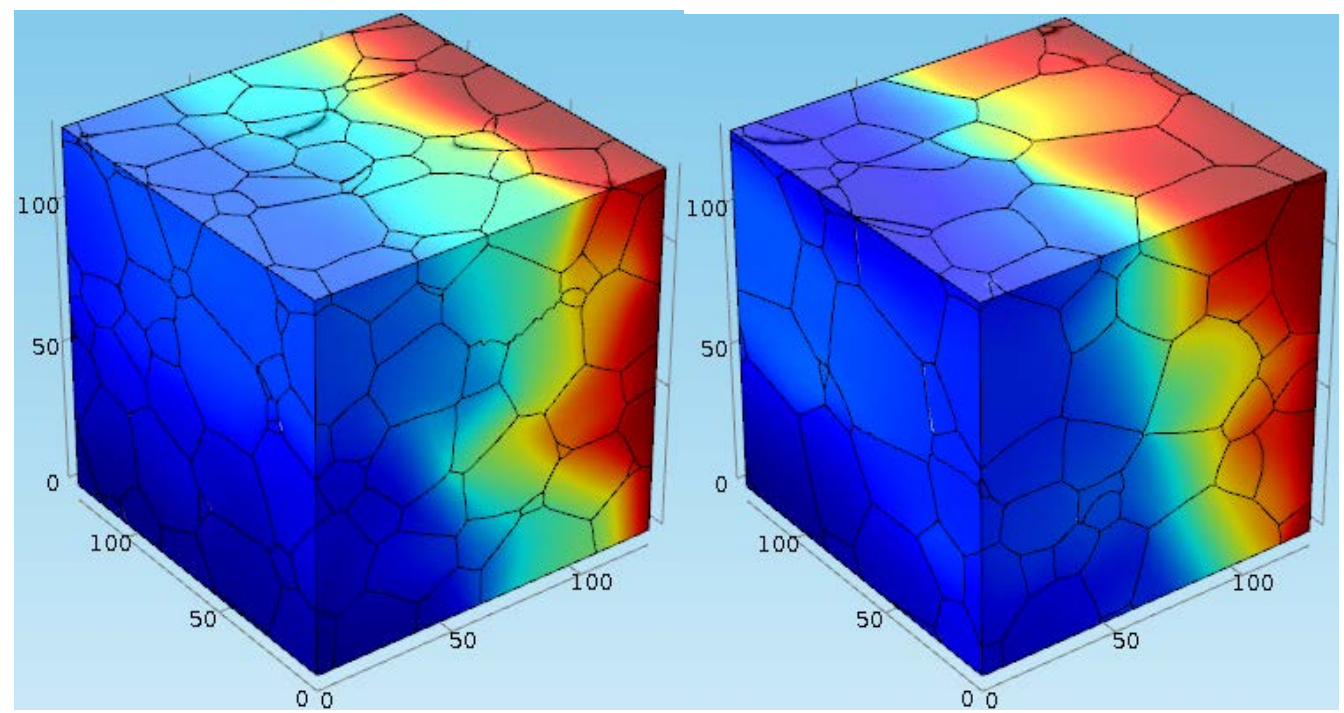

(a)

(b)

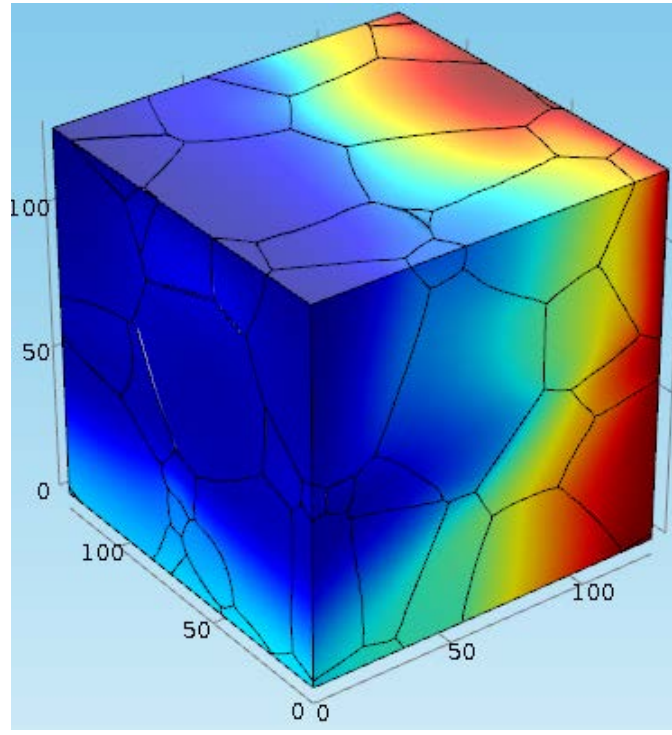

(c)

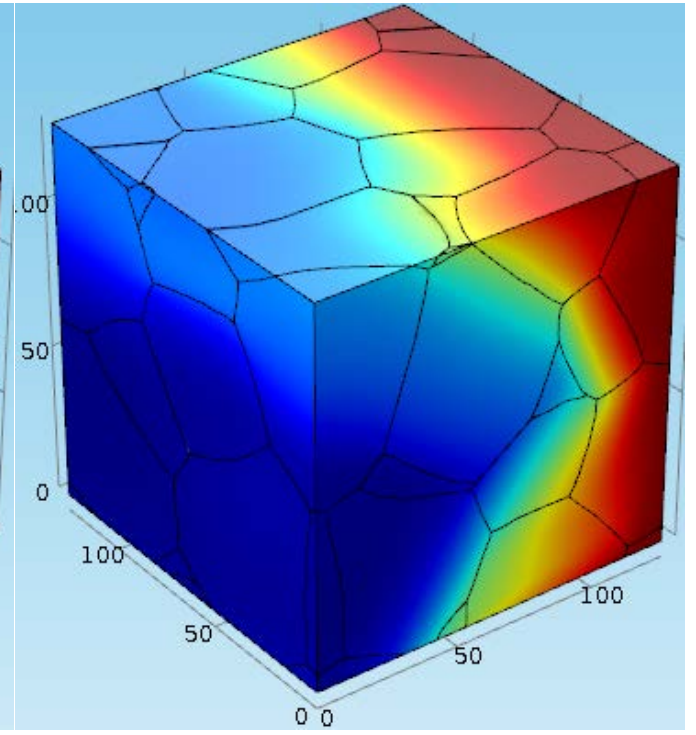

Mole fraction $\mathrm{x}$ in $\mathrm{Li}_{x} \mathrm{CoO}_{2}$

$\Delta 0.61$

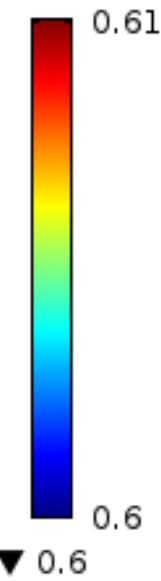

Fig. $4 \mathrm{Li}$ ion concentration profiles (mole fraction $\mathrm{x}$ in $\mathrm{Li}_{\mathrm{x}} \mathrm{CoO}_{2}$ ) in four $\mathrm{Li}$ ion diffusion microstrucutre models, at $50 \mathrm{~s}$ for $\beta=0.01$. (a) Grain size is $1.84 \mu \mathrm{m}$. (b) Grain size is $2.14 \mu \mathrm{m}$. (c) Grain size is $2.56 \mu \mathrm{m}$. (d) Grain size is $2.70 \mu \mathrm{m}$. 


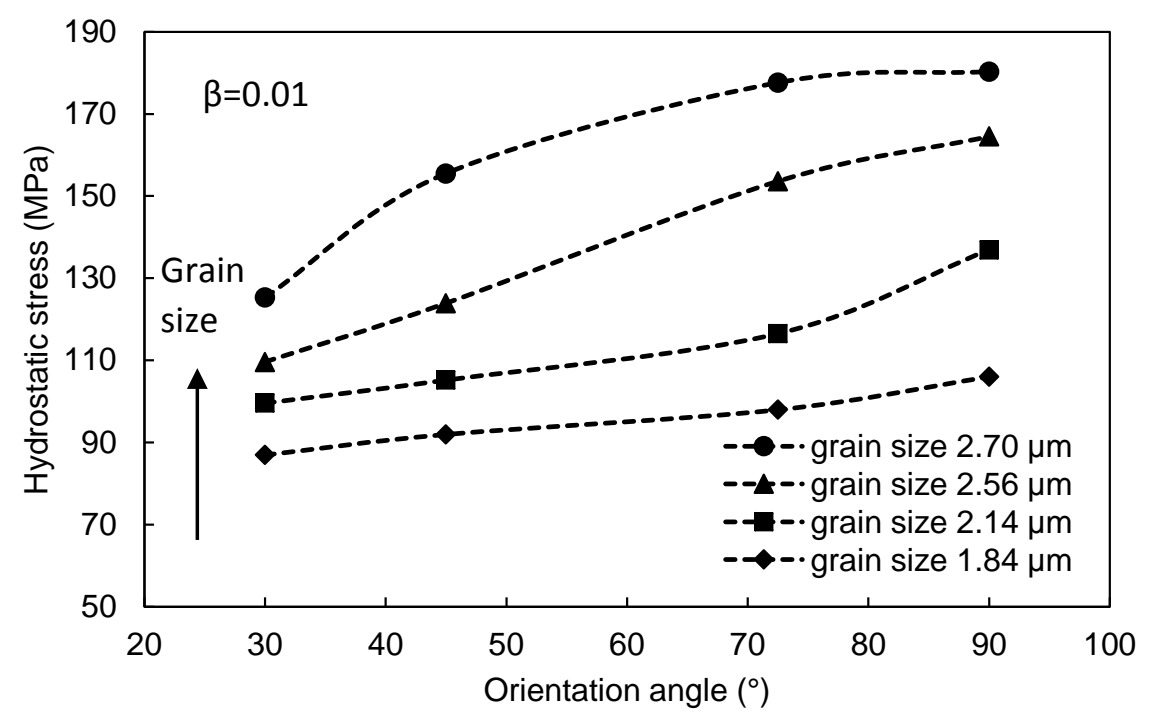

(a)

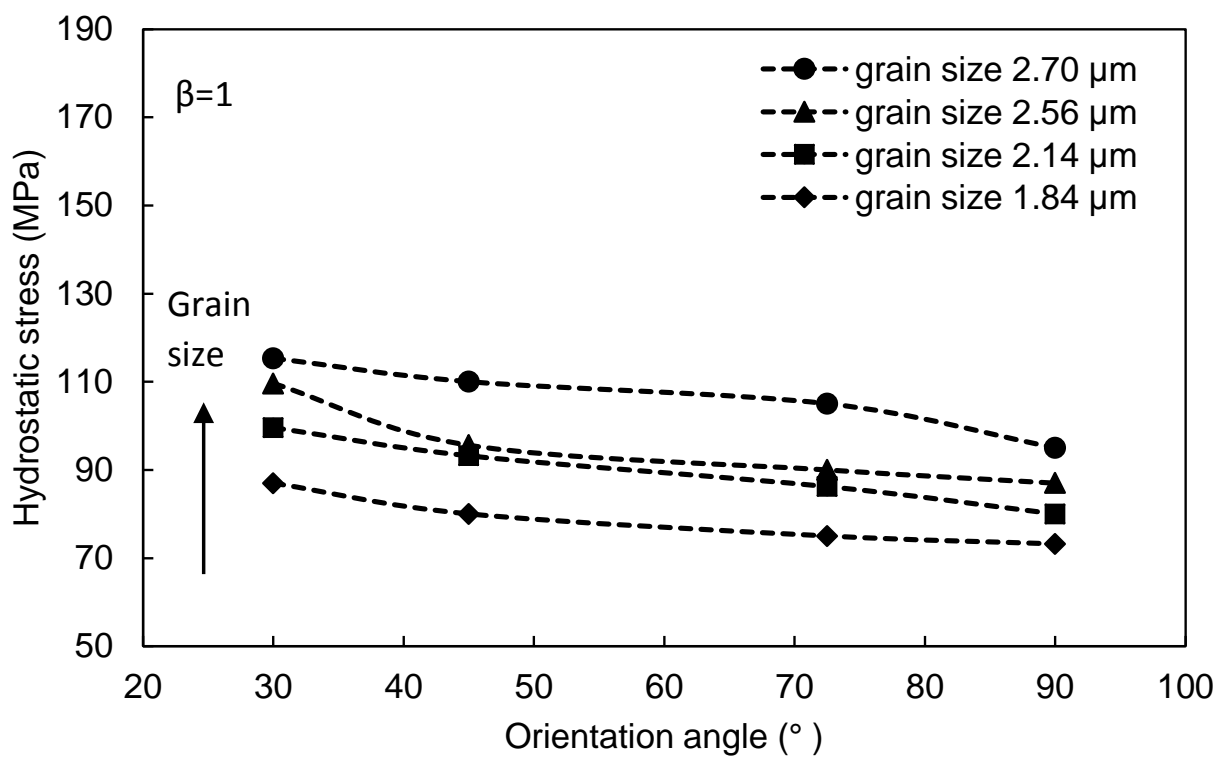

(b)

Fig. 5 Dependence of the hydrostatic stress on various grain sizes and different orientation angles.

(a) $\beta=0.01$ (b) $\beta=1$. Dashed lines are guide to the eyes. 


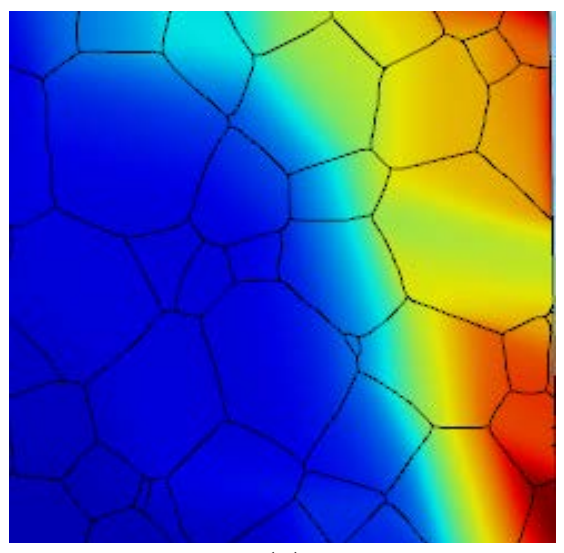

(a)

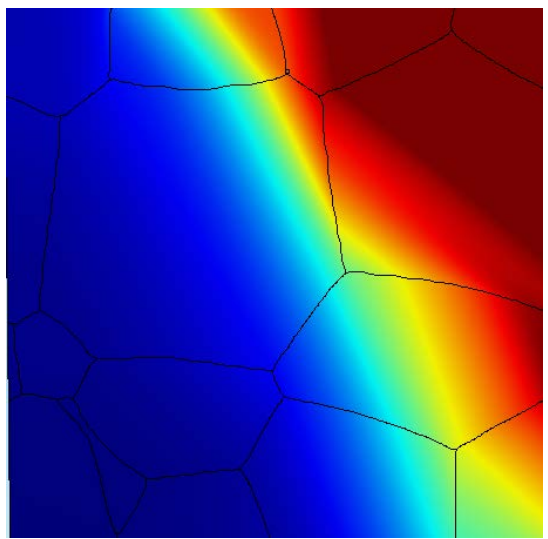

(c)

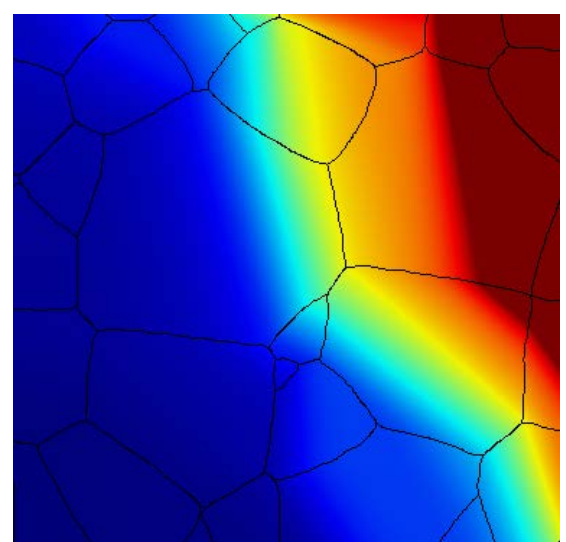

(b)
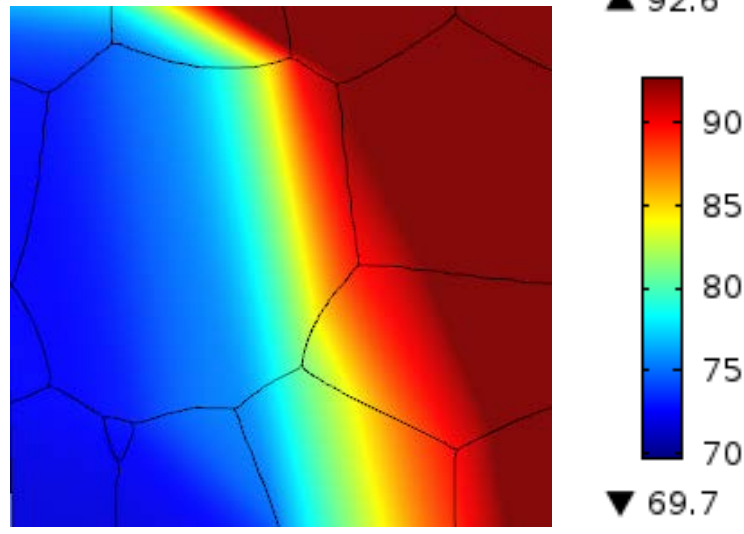

(d)
Hydrostatic stress (MPa)

வ 92.6 85

80

5

Fig. 6 Hydrostatic stress profiles for microstructures with different grain sizes. The profile shown is a cut plane at $\mathrm{z}=6.4 \mu \mathrm{m}$ at $\mathrm{t}=50 \mathrm{~s}, \beta=0.01$, mean $\alpha=\beta=45^{\circ}$. (a) Grain size is $1.84 \mu \mathrm{m}$. (b) Grain size is $2.14 \mu \mathrm{m}$. (c) Grain size is $2.56 \mu \mathrm{m}$. (d) Grain size is $2.70 \mu \mathrm{m}$. 
Mole fraction $\mathrm{x}$ in $\mathrm{Li}_{x} \mathrm{CoO}_{2}$

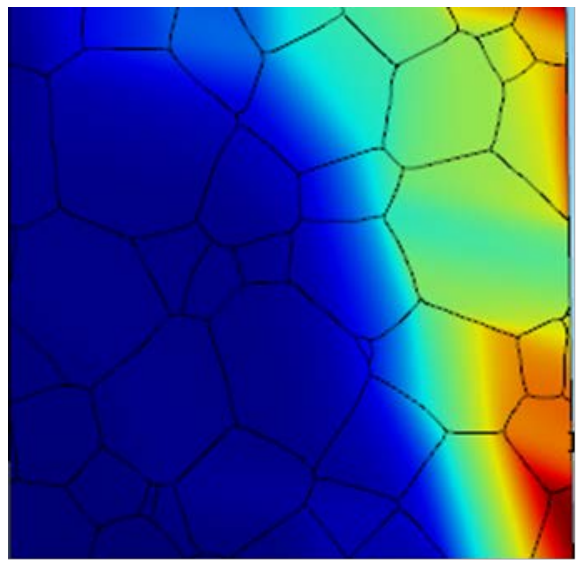

$\beta=0.01$ (a)

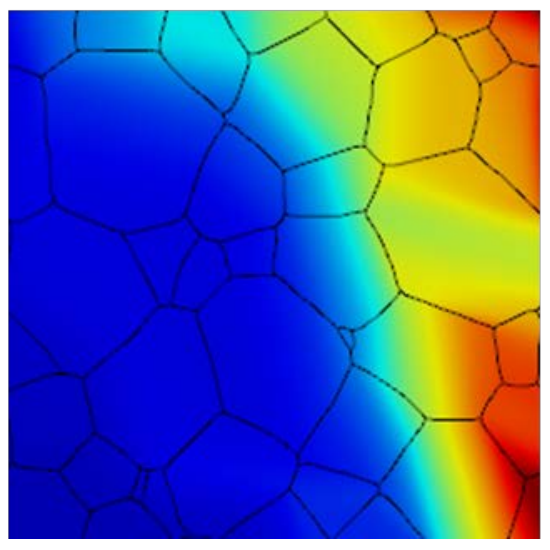

$\beta=0.01$

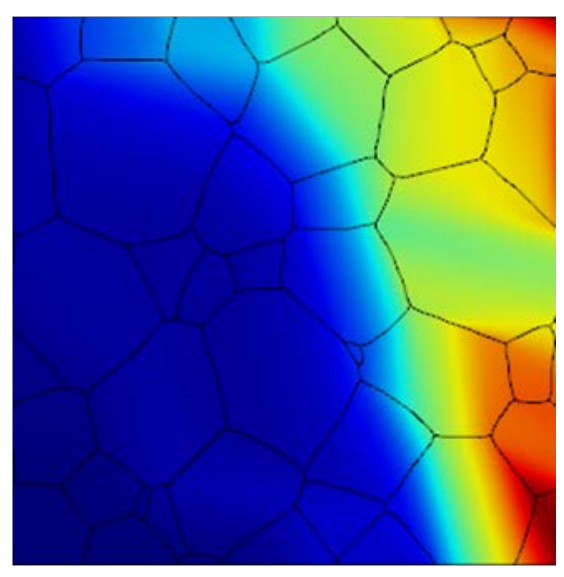

$\beta=1$

$\Delta 0.6$

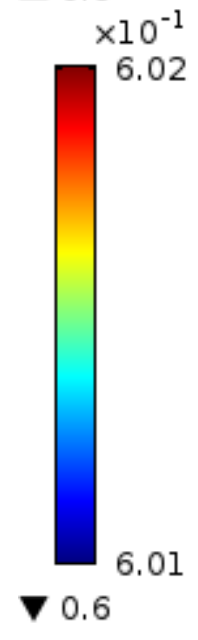

Hydrostatic stress (MPa)

$\Delta 69.6$

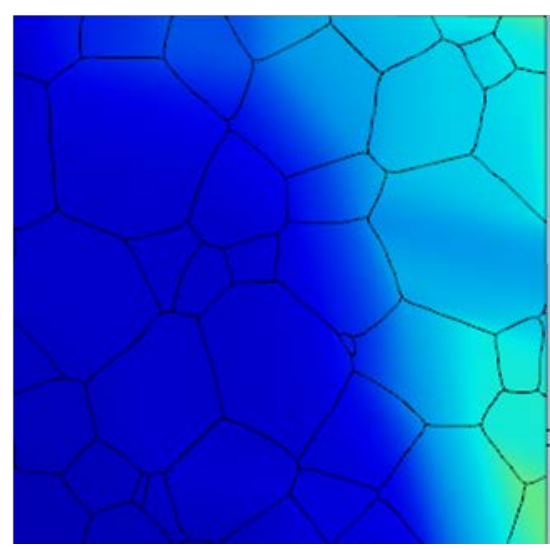

$\beta=1$

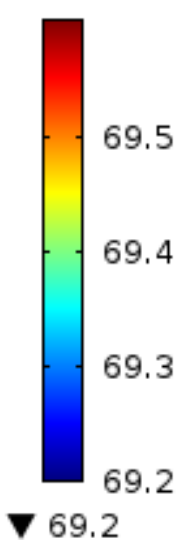

69.2

(b)

Fig. 7 (a) Li ion concentration (mole fraction $\mathrm{x}$ in $\mathrm{Li}_{\mathrm{x}} \mathrm{CoO}_{2}$ ) profiles; and (b) Hydrostatic stress profiles for $1.84 \mu \mathrm{m}$ with different grain boundary diffusivities. The plane shown is a cut plane at $\mathrm{z}=6.4 \mu \mathrm{m}, \mathrm{t}=50 \mathrm{~s}$, and orienation angle $30^{\circ}$. 


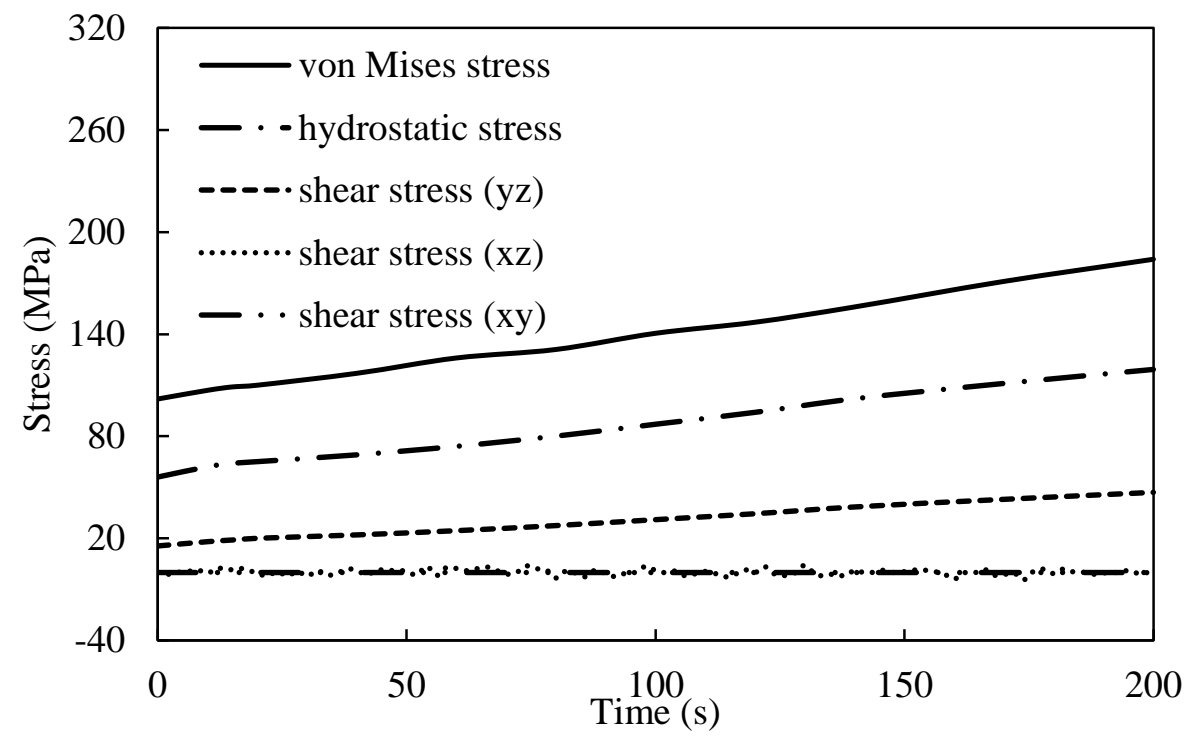

Fig. 8 Time history of averaged von Mises stress, hydrostatic stress and shear stresses of the microstructure with grain size $2.70 \mu \mathrm{m}, \beta=1$, and mean $\alpha=\beta=45^{\circ}$. 
Table 1 Boundary conditions

\begin{tabular}{|l|l|l|l|}
\hline & $(100)$ surface & $(100)$ surface & Other \\
& & & surfaces \\
\hline Diffusion & c= const. or $\mathrm{i}_{\mathrm{n}} / \mathrm{F}$ & $\vec{n} \cdot \nabla c=0$ & periodic \\
\hline Stress & free & fixed & periodic \\
\hline
\end{tabular}


Table 2 Parameters used in the simulation

\begin{tabular}{|l|l|}
\hline $\mathrm{k}_{0}\left(\mathrm{~cm}^{5 / 2} \mathrm{~mol}^{-1 / 2} \mathrm{~s}^{-1}\right)$ & $2.9 \times 10^{-6}[9]$ \\
\hline$\alpha_{\mathrm{a}}$ & 0.5 \\
\hline$\alpha_{\mathrm{c}}$ & 0.5 \\
\hline$D_{\text {self }}\left(\mathrm{cm}^{2} / \mathrm{s}\right)$ & $1 \times 10^{-9}[25]$ \\
\hline$D_{\text {self-caxis }}\left(\mathrm{cm}^{2} / \mathrm{s}\right)$ & $1 \times 10^{-11}[9]$ \\
\hline$\beta$ & 0.01 and 1 \\
\hline$d_{g b}(\mathrm{~nm})$ & 10 \\
\hline $\mathrm{E}(\mathrm{GPa})$ & 150 \\
\hline$v$ & 0.33 \\
\hline $\mathrm{C}_{\mathrm{max}}\left(\mathrm{mol} / \mathrm{m}^{3}\right)$ & $51555[9]$ \\
\hline$\Omega\left(\mathrm{m}^{3} / \mathrm{mol}\right)$ & $3.497 \mathrm{x} 10^{-6}[25]$ \\
\hline $\mathrm{i}_{\mathrm{n}}\left(\mathrm{A} / \mathrm{m}^{2}\right)$ & 2 \\
\hline
\end{tabular}

